\title{
Mesomelic dysplasia, Kantaputra type
}

INSERM

\section{Source}

INSERM. (1999). Orphanet: an online rare disease and orphan drug data base. Mesomelic dysplasia, Kantaputra type. ORPHA:1836

Mesomelic dysplasia Kantaputra type (MDK) is a rare skeletal disease characterized by symmetric shortening of the middle segments of limbs and short stature. 